\title{
A Novel Therapy for Haemorrhoids: Hand-sewn Haemorrhoidopexy using a Modified Anoscope
}

J-H Wang, R-S Fei, Z Wang, J-J Lin, J-H Xu, W-B Chen

\begin{abstract}
Purpose: Grades III and IV haemorrhoids have been preferentially treated with surgery for years. The decision to pursue surgical therapy for haemorrhoids is based on the severity of symptoms and the traditional classification of haemorrhoid prolapse. In this study, an alternative technique known as hand-sewn haemorrhoidopexy (HHP) was conducted using a modified anoscope.

Methods: A total of 51 patients requiring surgical treatment for grades III and IV prolapsing haemorrhoids were treated by HHP. Hospital stay duration, costs, time of work-off, operative time, wound healing-time, complications and outcomes were recorded after the operation.

Results: Shorter wound healing-time and lower complication rates were observed after the patients were subjected to HHP. These patients also exhibited better tolerance for the operation and incurred significantly lower costs than patients who were treated with other therapies.

Conclusions: Hand-sewn haemorrhoidopexy using is a safe, effective and painless surgical procedure to treat patients with grades III and IV or mixed haemorrhoids.
\end{abstract}

Keywords: Hand-sewn haemorrhoidopexy, internal haemorrhoids, mixed haemorrhoids

\section{Una Terapia Novedosa para las Hemorroides: Hemorroidopexia por Sutura Manual Mediante un Anoscopio Modificado \\ J-H Wang, R-S Fei, Z Wang, J-J Lin, J-H Xu, W-B Chen}

\begin{abstract}
RESUMEN
Propósito: Las hemorroides de grados III y IV han sido preferentemente tratadas mediante cirugía durante muchos años. La decisión de continuar la terapia quirúrgica para las hemorroides se basa en la severidad de los sintomas y la clasificación tradicional del prolapso hemorroidal. En este estudio, se llevó a cabo una técnica alternativa conocida como hemorroidopexia por sutura manual (HPM) mediante un anoscopio modificado.

Métodos: Un total de 51 pacientes que requerían tratamiento quirúrgico de hemorroides prolapsadas de grados III y IV fueron tratados por HPM. Tras la operación se registraron la duración de la estancia hospitalaria, los costos, el tiempo de trabajo, el tiempo de operación, el tiempo de curación de las heridas, las complicaciones, y los resultados.

Resultados: En los pacientes fueron operados con HPM, se observó un menor tiempo de curación de las heridas, y tasas de complicaciones más bajas. Estos pacientes mostraron también una mejor tolerancia de la operación y tuvieron costos significativamente más bajos que los pacientes que fueron tratados con otras terapias.
\end{abstract}

From: Department of Anorectal Surgery, the First Affiliated Hospital, College of Medicine, Zhejiang University, Hangzhou 310003, PR China.
Correspondence: Dr W-B Chen, Department of Anorectal Surgery, The First Affiliated Hospital, College of Medicine, Zhejiang University, No. 79 Qingchun Road,Hangzhou 310003. PR China. Email: jhsfen@126.com

*Co-first authors: Jin-Hai Wang and Ru-Shan Fei. These authors contributed equally to this work and should be considered co-first authors. 
Conclusiones: Hemorroidopexia manual es un procedimiento quirúrgico seguro, eficaz e indoloro con el cual tratar a los pacientes con hemorroides de grados III y IV, o hemorroides mixtas.

Palabras claves: Haemorroidopexia por sutura manual, haemorroides internas, haemorroides mixtas

West Indian Med J 2017; 66 (2): 353

\section{INTRODUCTION}

Internal haemorrhoids (referred to as "haemorrhoids") grow as a result of the chronic engorgement of the submucosal venous plexus of the anal canal and originate above the dentate line (1). Several forms of haemorrhoids require various treatments. For instance, Grade III haemorrhoids require manual reduction; grade IV haemorrhoids are non-reducible (2). These forms of haemorrhoids are surgically removed by excision and fixation (3). Such surgical options for the treatment of haemorrhoids have changed from conventional total excision to partial resection (4). Furthermore, an increasing number of minimally invasive treatment options, including procedure for prolapse and haemorrhoids (PPH), mucopexy with or without mucosal resection and haemorrhoid artery ligation (5-7), have been proposed to manage grade III haemorrhoids. However, serious complications, such as anal stenosis, incontinence, massive bleeding, pyaemia and death, have been associated with PPH (8). An increased risk of recurrence is also a consequence of these minimally invasive and less painful treatments (9). Prolapse and haemorrhoids is also conducted in large cities in China because of the lower costs of the stapler used in this procedure. In rural areas, many patients cannot afford expensive staplers, which cost approximately US\$500. In this study, an alternative technique known as handsewn haemorrhoidopexy (HHP) was used to treat 51 patients with haemorrhoids by partial resection.

\section{SUBJECTS AND METHODS}

Using a modified anoscope, we performed HHP to treat 51 patients (21 males and 30 females) with a median age of $60.3 \pm 15.1$ years (age ranged from 24 years to 66 years). These patients suffered from grades III and IV or mixed haemorrhoids from February 2008 to February 2011. This study was conducted in accordance with the Declaration of Helsinki. This study was conducted with approval from the Ethics Committee of the First Affiliated Hospital, College of Medicine and Zhejiang Uni- versity, Zhejiang, China. Written informed consent was obtained from the participants.

\section{Operating procedure}

Under epidural anaesthesia, the patients were placed in a prone position for the perineal operation. An antiseptic was applied on the distal part of the rectum. Afterwards, the anal canal was gently dilated for a four-finger admission. A modified anoscope was composed of a $50 \mathrm{~mL}$ plastic syringe with a rectangle window $(1.5 \mathrm{~cm} \times 5 \mathrm{~cm}$ in size) opening against the syringe wall. This instrument was carefully rotated into the anal cavity until the haemorrhoid block was exposed to the open window (Fig. 1).

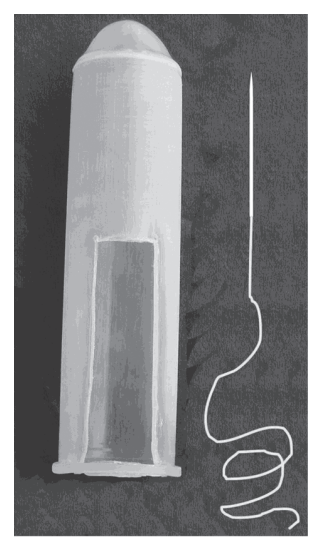

Fig. 1: The modified anoscopy made of a $50 \mathrm{~mL}$ plastic syringe with a rectangle window about $1.5 \times 5 \mathrm{~cm}$ in size opened against the syringe wall.

Afterwards, $1^{\#}$ Dexon suture with a straight needle was used for continuous submucosal blanket suturing. In suturing, the needle was inserted at $0.5 \mathrm{~cm}$ proximal to the dental line and then withdrawn at the proximal edge of the haemorrhoid block (Figs. 2A and 2B). The internal haemorrhoid tissue was continuously sutured until the elevated part of the haemorrhoid block showed a flat appearance (Fig. 2C). 


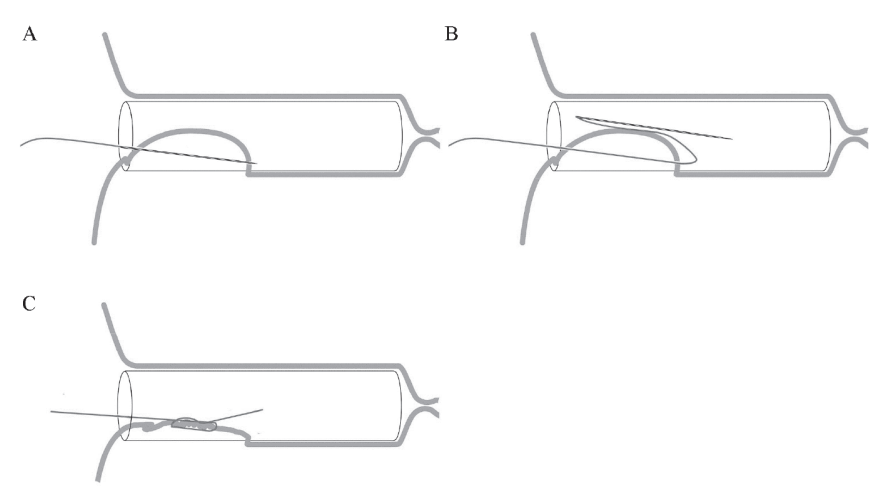

Fig. 2: Diagram of the hand-sewn haemorrhoidopexy procedure. (A) Submucosal blanket suturing by inserting the needle $0.5 \mathrm{~cm}$ proximal to the dental line with a straight needle; (B) The needle was withdrawn at the proximal edge of haemorrhoid block; and (C) An elevated part of haemorrhoid block showed flat appearance after continuous suture.

The same method was applied to suture the remaining haemorrhoid blocks. After HHP, the sutured mucosa showed a flat appearance without mucosal laceration or bleeding. The external haemorrhoids normally retracted into the anal cavity (Fig. 3). In some instances, residual skin tags are excised and the incision is sutured using 4-0" Dexon.

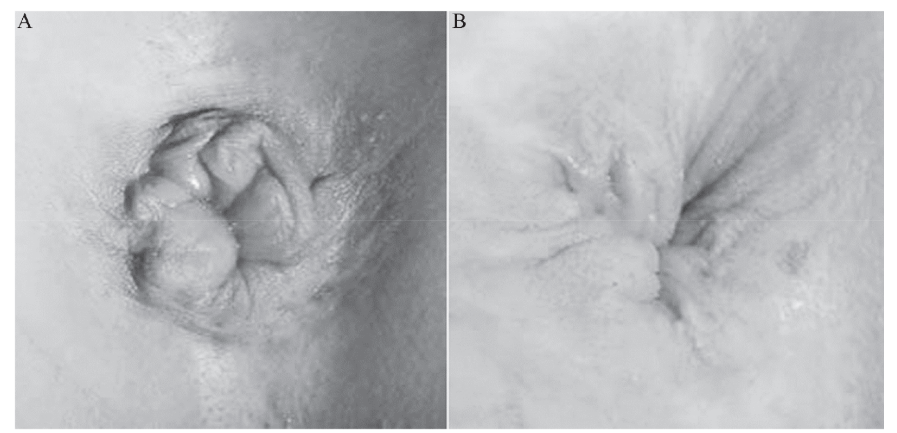

Fig. 3: Pre- and post-surgery of external haemorrhoids.

(A) Manifestation of pre-surgery external haemorrhoids.

(B) Retraction of the post-surgery external haemorrhoids back into the anus.

\section{RESULTS}

The mean duration of the operation was $39.98 \pm 9.5$ minutes. Blood loss during the operation was approximately $20.0 \mathrm{~mL}$ (range $=15.0 \mathrm{~mL}$ to $25.0 \mathrm{~mL}$ ). None of the patients developed serious postoperative complications. The postoperative recovery time was $9.63 \pm 2.6$ days. The average length of stay of the patients in the hospital was $6.84 \pm 1.9$ days. At the early-stage of postoperation, two patients (3.9\%) showed anal margin swelling, which was the most common minor complication among the complications observed in this study. Nevertheless, no patient needed hospital readmission because of other symptoms. The symptoms resolved within four weeks after surgery.

All of the patients were followed up for one-year. Visual analogue scale (VAS) was used to assess wound pain during the follow-up period. The following VAS scores were obtained: 40 cases, 0 point; 7 cases, 1 point; 3 cases, 2 points; and 1 case, 3 points. In addition, three geriatric patients $(5.9 \%)$ developed anal incontinence and exhibited poor anal function before surgery. Four patients developed recurrent prolapse, the overall one-year recurrence rate of prolapsing haemorrhoids was 3.9\% $(2 / 51)$. No patient developed faecal urgency and incontinence postoperatively or anal stenosis from the fourth month onwards during the follow-up period. A total of 49 patients were satisfied with HHP, with $98 \%$ overall satisfaction rate.

\section{DISCUSSION}

Thomson described the prolapse of the anal mucosa and the physiological importance of the anal cushion. Handsewn haemorrhoidopexy is performed to restore the fixation of the haemorrhoidal cushion and eliminate the anal mucosa prolapse (1). Hand-sewn haemorrhoidopexy showed satisfactory results of the surgical management in 51 patients with haemorrhoids. Using the HHP technique, we partially preserved the mucosal bridges; this procedure contributed to better rectal compliance during defaecation. Only three geriatric patients $(5.9 \%)$ suffered from gas or fluid incontinence. The inflammation at the site with a stapled ring may cause urgency (10-12), but no urgency was observed in our study.

This result could be attributed to partial mucus resection without any foreign body, leading to fewer episodes of faecal urgency and incontinence after HHP.

Postoperative pain after haemorrhoidectomy is a common problem. Stapled techniques are associated with acute and chronic pain (13), which may be caused by chronic inflammation (11) or improper location of stapled instruments that stimulate the squamous epithelium of the anoderm (14). In the present study, postoperative pain was observed in some cases probably because HHP is associated with the partial resection of the rectal mucosa to spare the mucosal bridges without a stapled instrument. Thus, inflammation and straining were reduced, particularly during the first postoperative defaecation, resulting in less postoperative pain. 
Considering the surgical treatments for patients with haemorrhoid, we should determine the mechanism by which postoperative pain and operation duration are reduced in patients residing in developed countries (1517), but costs should be considered, particularly for patients with low-income. Many alternative surgical haemorrhoidectomy techniques require assistants or specific instruments, which incur additional surgery costs. Such costs are not covered by health insurance in some developing countries. Thus, HHP is a very effective alternative to treat patients with haemorrhoids and are in the low-income bracket. Furthermore, HHP is a safe method, causing less pain, fast recovery and low-cost.

Studies have demonstrated that $\mathrm{PPH}$ result in more advantages than traditional Milligan-Morgan haemorrhoidectomy (18-21). By comparison, HHP can be safely applied to patients with haemorrhoids and achieve the same or better results. No severe complications were observed in patients subjected to HHP in this study possibly because of the small number of samples. Handsewn haemorrhoidopexy is a good choice for haemorrhoid surgery, particularly for patients who have low-income and are residing in developing countries.

In this study, no relapse from HHP was observed possibly because of the short follow-up period. After $\mathrm{PPH}$, the recurrence rate of patients with grade IV internal-external haemorrhoids can reach a maximum of $58.9 \%$, which is higher than that in traditional surgical treatments (19). Further studies should be conducted to determine whether or not the recurrence rate of HHP is as high as that of minimally invasive and less painful treatments.

\section{CONCLUSION}

In conclusion, the modified HHP is a safe, effective and painless surgical procedure with a high satisfaction rate for the patients with grades III and IV or mixed haemorrhoids. The low-cost and fast recovery of the patients who were subjected to HHP indicated that the HHP procedure could be a valid alternative surgical option, particularly for patients in the low-income bracket.

\section{AUTHOR CONTRIBUTION}

$\mathrm{Xu} \mathrm{JH}$ and Chen WB contributed to conception and design of the surgery, Wang JH contributed to analysis and interpretation of data, drafting and revising the article; Fei RS contributed to acquisition of data and drafting the article and final approval of the version to be published; Wang $\mathrm{Z}$ contributed to final approval of the version to be published; Lin JJ contributed to revising the article.

\section{CONFLICTS OF INTEREST}

None.

\section{REFERENCES}

1. Thomson WH. The nature of haemorrhoids. Br J Surg 1975; 62: 542-52.

2. Sardinha TC, Corman ML. Hemorrhoids. Surg Clin North Am 2002; 82: 1153-67.

3. Khan S, Pawlak SE, Eggenberger JC, Lee CS, Szilagy EJ, Wu JS et al. Surgical treatment of hemorrhoids: prospective, randomized trial comparing closed excisional hemorrhoidectomy and the Harmonic Scalpel technique of excisional hemorrhoidectomy. Dis Colon Rectum 2001; 44: 845-9.

4. Lin HC, He QL, Ren DL, Peng H, Xie SK, Su D et al. Partial stapled hemorrhoidopexy: a minimally invasive technique for hemorrhoids. Surg Today 2012; 42: 868-75.

5. Longo A. Treatment of hemorhoids disease by reduction of mucosa and hemorhoidal prolapse with a circular suturing device: a new procedure; Proceedings of the 6th world Congresa of Endoscopic Surgery; 1998 Jun 3-6; Rome, Italy. Bologna: Monduzzi Publishing; 1998: 777-84.

6. Lucarelli P, Picchio M, Caporossi M, De Angelis F, Di Filippo A, Stipa F et al. Transanal haemorrhoidal dearterialisation with mucopexy versus stapler haemorrhoidopexy: a randomised trial with long-term follow-up. Ann R Coll Surg Engl 2013; 95: 246-51.

7. Yilmaz İ, Sücüllü İ, Karakaş DÖ, Özdemir Y, Yücel E, Akin ML. Doppler-guided hemorrhoidal artery ligation: experience with 2 years follow-up. Am Surg 2012; 78: 344-8.

8. McCloud JM, Jameson JS, Scott AN. Life-threatening sepsis following treatment for haemorrhoids: a systematic review. Colorectal Dis 2006; 8: 748-55.

9. Altomare DF, Giuratrabocchetta S. Conservative and surgical treatment of haemorrhoids. Nat Rev Gastroenterol Hepatol 2013; 10: $513-21$.

10. Mlakar B, Kosorok P. Complications and results after stapled haemorrhoidopexy as a day surgical procedure. Tech Coloproctol 2003; 7: 164-8.

11. Fueglistaler P, Guenin MO, Montali I, Kern B, Peterli R, von Flüe $\mathrm{M}$ et al. Long-term results after stapled hemorrhoidopexy: high patient satisfaction despite frequent postoperative symp-toms. Dis Colon Rectum 2007; 50: 204-12.

12. Boccasanta P, Venturi M, Roviaro G. What is the benefit of a new stapler device in the surgical treatment of obstructed defecation? Three-year outcomes from a randomized controlled trial. Dis Colon Rectum 2011; 54: 77-84.

13. Shao WJ, Li GC, Zhang ZH, Yang BL, Sun GD, Chen YQ. Systematic review and meta-analysis of randomized controlled trials comparing stapled haemorrhoidopexy with conventional haemorrhoidectomy. Br J Surg 2008; 95: 147-60.

14. Cheetham MJ, Mortensen NJ, Nystrom PO, Kamm MA, Phillips RK. Persistent pain and faecal urgency after stapled haemorrhoidectomy. Lancet 2000; 356: 730-3.

15. Pattana-Arun J, Sooriprasoet N, Sahakijrungruang C, Tantiphlachiva K, Rojanasakul A. Closed vs ligasure hemorrhoidectomy: a prospective, randomized clinical trial. J Med Assoc Thai 2006; 89: 453-8.

16. Sugimoto T, Tsunoda A, Kano N, Kashiwagura Y, Hirose K, Sasaki T. Randomized, Prospective, Double-blind, Placebo- 
Controlled Trial of the Effect of Diltiazem Gel on Pain after Hemorrhoidectomy. World J Surg 2013; 37: 2454-7.

17. Ala S. Efficacy of cholestyramine ointment in reduction of postoperative pain and pain during defecation after open hemorrhoidectomy: results of a prospective, single-center, randomized, double-blind, placebo-controlled trial: reply. World J Surg 2013; 37: 2009-10.

18. Ganio E, Altomare DF, Milito G, Gabrielli F, Canuti S. Longterm outcome of a multicentre randomized clinical trial of stapled haemorrhoidopexy versus Milligan-Morgan haemorrhoidectomy. Br J Surg 2007; 94: 1033-7.
19. Ortiz H. Stapled hemorrhoidopexy versus Milligan-Morgan hemorrhoidectomy. Ann Surg 2007; 245: 155-6.

20. Jayaraman S, Colquhoun PH, Malthaner RA. Stapled versus conventional surgery for hemorrhoids. Cochrane Database Syst Rev 2006; CD005393.

21. Kim JS, Vashist YK, Thieltges S, Zehler O, Gawad KA, Yekebas EF et al. Stapled hemorrhoidopexy versus milligan-morgan hemorrhoidectomy in circumferential third-degree hemorrhoids: long-term results of a randomized controlled trial. J Gastrointest Surg 2013; 17: 1292-8. 